vexample, more than 100 years ago, both intrinsic and instrumental values were used in the creation of Yellowstone National Park in Wyoming, and when Californians spurred the broader environmental movement in the United States by using economic studies of the value of birds alongside compelling speeches about the purity and grandeur of nature?

These values need not be in opposition, although they do reflect the hard choices that conservation often faces. They can instead be matched to contexts in which each one best aligns with the values of the many audiences that we need to engage. Those on the side of intrinsic value will argue that by recognizing the many ways in which people benefit from nature, we cheapen nature and miss opportunities to save components of it that have little or no obvious value to people. This is a valid concern, and one of many reasons why we must continue to uphold intrinsic values to audiences who share those values, or may be inspired towards them. However, instrumental values will remain more powerful for other audiences, and should be used in the many contexts where broadening support for conservation is essential ${ }^{4}$.

Clearly, all values will not be equally served in every context. Approaching conservation problems with representative perspectives and a broad base of respect, trust, pragmatism and shared understanding will more quickly and effectively advance our shared vision of a thriving planet. Prominent institutions already embrace multiple voices and values. For example, the field's signature international treaty, the Convention on Biological Diversity, calls for the conservation of biodiversity, and for the sustainable use and equitable sharing of its benefits. Some countries leading in this area, such as Mexico, Costa Rica and Colombia, have followed suit, capturing these joint interests in their own governing language.

\section{PRACTICAL ACTION}

What now? Academic training of conservation scientists should more accurately portray the rich, global history of the field, introducing students to the diverse ways in which nature has been valued and conserved for centuries. More forums at conferences, in journals and on social media are needed to elevate the voices of scientists and practitioners from under-represented genders, cultures and contexts. Conservation organizations and scientists can embrace all plausible conservation actors, from corporations to governmental agencies, faith-based organizations and interested individuals, and advance conservation efforts when they can benefit people and when there is no obvious human-centric goal.

These efforts must be underpinned by a stronger focus on synthesizing and expanding the evidence base that can identify what works and what fails in conservation so that we can move from philosophical debates to rigorous assessments of the effectiveness of actions. And we must encourage the full breadth of conservation scientists and practitioners to engage with the media so that coverage reflects the true range of opinion (for example, the 240 co-signatories listed are ready for interview) rather than the polarized voices of a few. To add your name to this petition, visit diverseconservation.org.

It is time to re-focus the field of conservation on advancing and sharing knowledge in all relevant disciplines and contexts, and testing hypotheses based on observations, experiments and models ${ }^{10}$. We call for an end to the fighting. We call for a conservation ethic that is diverse in its acceptance of genders, cultures, ages and values.

Heather Tallis is lead scientist at the Nature Conservancy in Santa Cruz, California, USA. Jane Lubchenco is professor of marine biology and of zoology at Oregon State University in Corvallis, Oregon, USA. e-mail:htallis@tnc.org

1. Gudynas, E. in La Naturaleza con Derechos: De la Filosofía a la Política 239-258 (AbyaYala, Universidad Politécnica Salesiana, 2011).

2. Soulé, M. Cons. Biol. 27, 895-897 (2013).

3. Reid, W. V. et al. Nature 443, 749 (2006).

4. Kareiva, P. \& Marvier, M. BioSci. 62, 962-969 (2012).

5. Toledo, V. M. \& Barrera-Bassols, N. La Memoria Biocultural (Icaria, 2014).

6. Max, D. T. 'Green Is Good' The New Yorker (12 May 2014).

7. UNESCO Institute for Statistics. Women in Science: UIS Fact Sheet (UNESCO, 2012).

8. Carson, R. Silent Spring (Houghton Mifflin, 1962).

9. Alagona, P. S. After the Grizzly: Endangered

Species and the Politics of Place in California (Univ. California Press, 2013).

10.Chapin III, F. S. et al. Ecosphere 2, 89 (2011).

For a full list of co-signatories and further reading on this topic, see go.nature.com/tezttv.

\title{
A to-do list for the world's parks
}

\author{
Experts share their priorities for what must be done to make \\ protected areas more effective at conserving global biodiversity.
}

BOB PRESSEY

Maximize returns on conservation

Professor, Australian Research
Council Centre of Excellence for Coral
Reef Studies, James Cook University

Protected areas are meant to preserve biodiversity, but practice, measures of progress and targets do not reflect this role.
Governments and non-governmental organizations usually concentrate on politically palatable measures, such as numbers of hectares. Measures of progress and targets for protected areas should focus on placing protection where it can make the most difference.

A 2008 study estimated that only 7\% of protected forests in Costa Rica would have been lost if not protected (K. S. Andam et al. Proc. Natl Acad. Sci. USA 105, 16089-16094; 2008). These forests, like most protected areas worldwide, are in 'residual areas' those where direct human threats to biodiversity are low, and where 'protection' makes little difference. Misleadingly, target 11 of the Convention on Biological Diversity measures progress in percentages of land and sea protected. Meanwhile, the biodiversity of contested places continues to be eroded.

Performance metrics for protected areas should borrow from those in medicine, education and development. These fields all aim to maximize returns on investment. The language of programme evaluators is framed in terms of efficacy: what is the actual outcome of an intervention, compared with the outcome expected from no intervention?

For protected areas, efficacy means 


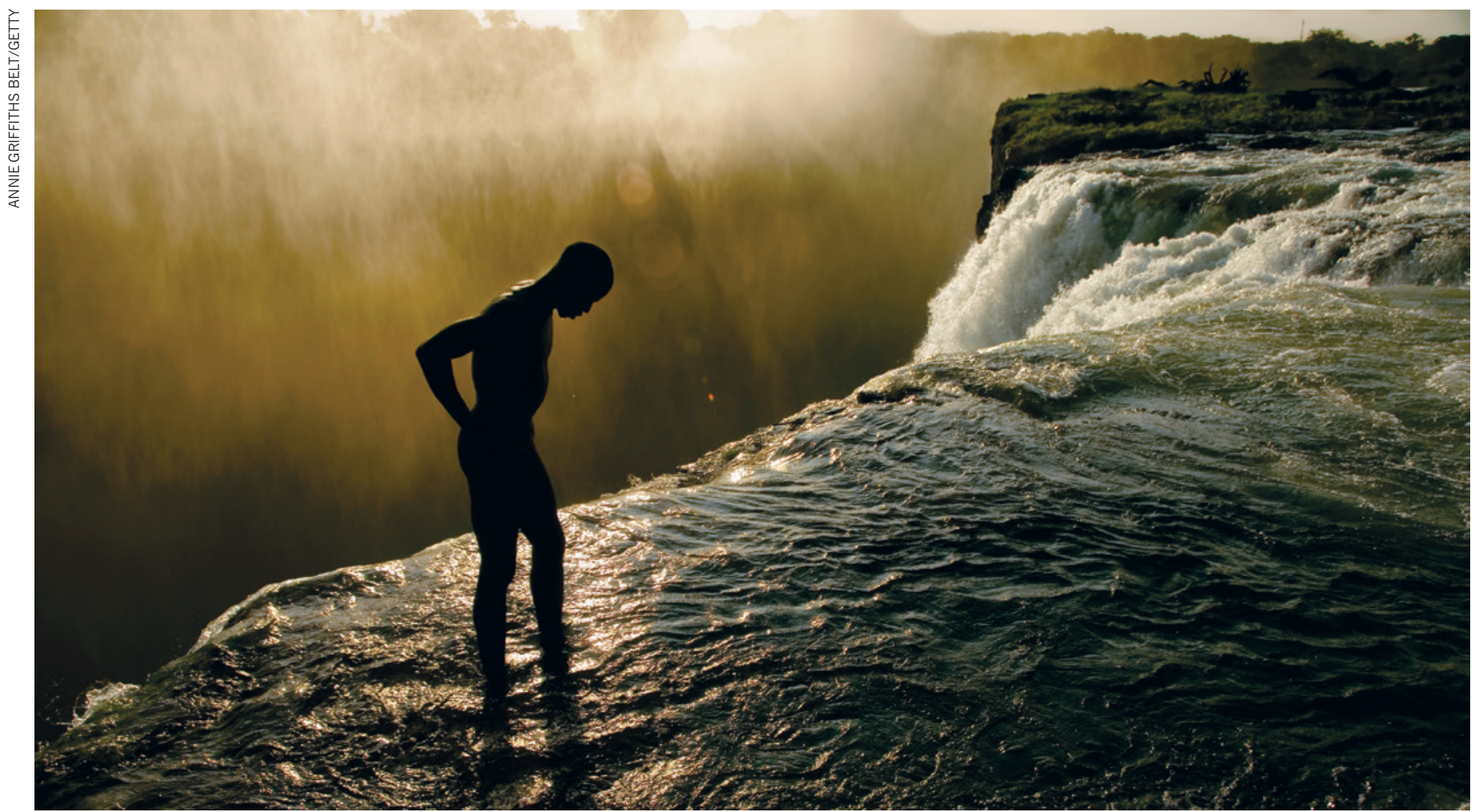

Areas surrounding Victoria Falls, on the Zambia-Zimbabwe border, are protected by national-park status.

avoiding the loss of species and maintaining the integrity of ecosystems. There are methods for estimating the losses that protection has prevented (to provide lessons) or could prevent (to set priorities). By these metrics, protected areas can be disappointing.

Success depends on which natural resources societies are willing to leave unexploited. The trends are not encouraging. Australia, for example, hosts this year's World Parks Congress, but most of its terrestrial and marine parks are residual, and the country's protected-area strategy has no quantitative targets for avoiding loss. The congress could make a real difference if it steers policies away from meaningless, counterproductive targets. Each year of delay means avoidable, irreversible loss of biodiversity.

\section{DOUGLAS J.MCCAULEY}

\section{Mega-parks need greater oversight}

Assistant professor in the department of ecology, evolution and marine biology, University of California, Santa Barbara

In September, US President Barack Obama created the world's largest marine protected area network by massively expanding the Pacific Remote Islands Marine National Monument (PRIMNM). Collectively, the
PRIMNM is more than five times the size of the United Kingdom. Its creation ups the ante in a conservation phenomenon without precedent on land or sea. The eight marine mega-parks (each more than 250,000 square kilometres) announced in the past five years have almost doubled the amount of protected area in the oceans.

Three actions must be taken to ensure that mega-parks do more good than harm for the world's seas. First, governments must recognize that conventional forms of monitoring for protected areas are not tenable in parks that are larger than some countries. To ensure that areas such as the PRIMNM do not become 'paper parks' - marked as protected on maps but exploited in reality - governments must explicitly fund the development and use of next-generation enforcement, such as satellite and dronebased patrols. Such tools are not cheap, but mega-parks will not function unless they are designated in budgets as well as on maps.

Second, policy-makers must enact regulations to manage highly mobile animals in the $96 \%$ of the ocean left unprotected. Many of the most at-risk species (including some turtle, shark and marine mammal species) are not fully protected, even in parks as big as the PRIMNM.

Lastly, the marine mega-park movement does not let us off the hook for protecting crucial marine habitats at smaller scales. Bigger is better with marine protected areas, but these benefits might not scale linearly. Although establishing 100 strategically placed, 10,000-square-kilometre marine parks is politically intractable, it would probably have done more for marine biodiversity than the establishment of just the PRIMNM.

If ineffectual practices can be avoided, environmental leaders will undoubtedly look back on this marine-mega-park era as one of the most important periods in the history of ocean conservation. If not, megaparks will be little more than mega-hype.

\section{LANCE MORGAN Protect diverse marine habitats}

\section{President of the Marine Conservation Institute}

A portfolio of well-protected, representative marine ecosystems - humankind's in situ seed vault for ocean life - is needed for biological and human resilience. Only about $2 \%$ of the ocean has any protection, and just $0.83 \%$ is 'no-take' reserves, where humans are not allowed to extract fish, oil or other resources. Marine biologists recommend that $20-30 \%$ of the ocean must be protected to maintain its biodiversity. This amount will provide enough abundance to restore depleted populations outside reserves.

To accelerate establishment of highly effective biodiversity refuges, the Marine Conservation Institute has initiated the 
Global Ocean Refuge System (GLORES). The prestige and social capital that comes from receiving the GLORES status can spur governments, much as 'green building' certification has helped the adoption of sustainable practices in construction.

Capturing a diversity of habitats is key. US national parks, for example, often encompass mountainous areas of the United States, but not prairies and wetlands. GLORES considers the effect of a protected area in the context of others. It accounts for marine biogeography and connectivity; for example, kelp forests occur in temperate biogeographic regions, whereas coral reefs occur in tropical regions.

GLORES criteria require effective monitoring and enforcement, whether by communities, scientists or other authorities. The goal is to create protected areas in all of the different ocean regions and habitats (shallow and deep, sandy and rocky bottoms, and more).

GLORES will be easier, cheaper and faster to implement than many other approaches. Protecting places is much less knowledgeintensive and less costly than managing marine species one by one or persuading countries to protect areas one by one (often small areas that fishers care least about).

\section{HUGH POSSINGHAM Represent ecosystems}

\section{Professor of mathematics and ecology, University of Queensland; Chair of conservation decisions, Imperial College London}

The Convention on Biological Diversity asks countries to conserve at least $17 \%$ of their land and $10 \%$ of their seas. It also calls for "ecological representation", the equitable coverage of species and habitats, but sets no quantitative targets. Representation is often ignored in designing systems of protected areas. For example, the koala is just one of many species that prefers under-protected fertile, wellwatered habitats that are also favoured for agriculture and other development.

There are better approaches. Representation can be highly efficient. In 2004, the Great Barrier Reef Marine Park Authority used extensive economic and ecological data to create a system of 'no-take' protected areas that conserved at least $20 \%$ of every habitat while covering only $33 \%$ of the region.

To help refocus priorities, our group created software called Marxan. It uses mathematical optimization to prioritize places to design efficient and representative protected areas. We have also developed a

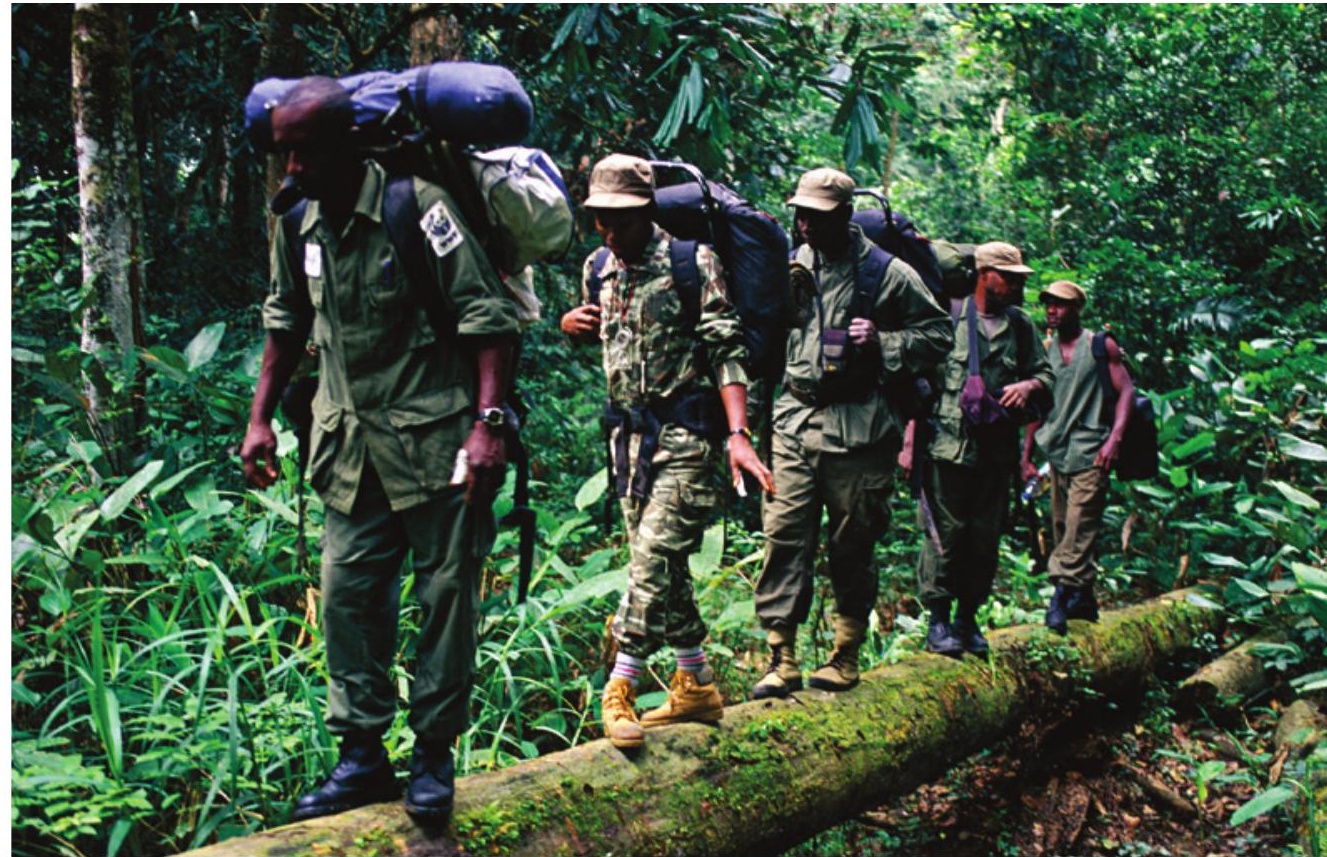

An anti-poaching team of the conservation group WWF on patrol in Minkébé National Park, Gabon.

new metric, protection equality, to measure equitable representation of habitats in a single number. It is a modification of the Gini coefficient commonly used to assess income inequality.

For example, the United States has a relatively large fraction of its land conserved, but its land protection equality is poor, only 0.33 . Australia, which has a policy for representation, has a smaller fraction of its land conserved but a higher land protection equality of 0.51 , a much more representative system. The protection equality of the Great Barrier Reef Marine Park is 0.80, more than any country. By contrast, the proposed re-zoning of Australia's Commonwealth waters is biased towards deeper waters and misses entire ecosystems.

We hope that this year's World Parks Congress will stimulate more-sophisticated tools for building representative systems of protected areas, and metrics for assessing them.

\section{LEEWHITE \\ Manage parks professionally}

\section{Executive secretary, Gabon National Parks Agency}

The special parts of our planet warrant and need exceptional stewardship. They are not getting it. We need a pact - between political leaders, civil society and conservation professionals - to increase the political capital of the environment.

Many of the world's rarest and most iconic species - gorillas, chimpanzees, orangutans, elephants, lions, tigers and pandas - survive almost exclusively in protected areas. In both developed and developing countries, protected areas often contain the richest, most pristine ecosystems. They also provide crucial ecosystem services. Mangrove parks succour fisheries and protect against floods (see page 32); forests provide clean, reliable water and help to regulate the climate. Tourism and leisure use of parks improve people's quality of life. If preserved, the biodiversity within parks could well yield as-yet-unknown medicines and other products.

We need to strengthen and professionalize park management. Too many of the developing world's protected areas are chronically underfunded. And government neglect often means that management falls to international non-governmental organizations (NGOs). Because this responsibility is rarely formalized, NGOs do not have a strong mandate to protect these areas well.

For example, in the late 1990s, the government of Gabon failed to take responsibility for Minkébé National Park, so the conservation group WWF stepped in. Despite spending millions of dollars, WWF was unable to stop the slaughter of elephants there: at least 16,600 elephants were lost between 2004 and 2012, mainly to cross-border poachers. In May 2011, the government deployed 120 military personnel to support parks staff; in October 2014, with the situation still not under control, it pledged to double those numbers.

The people who fight to preserve our natural and cultural treasures must be trained and backed by their nations. Only then 


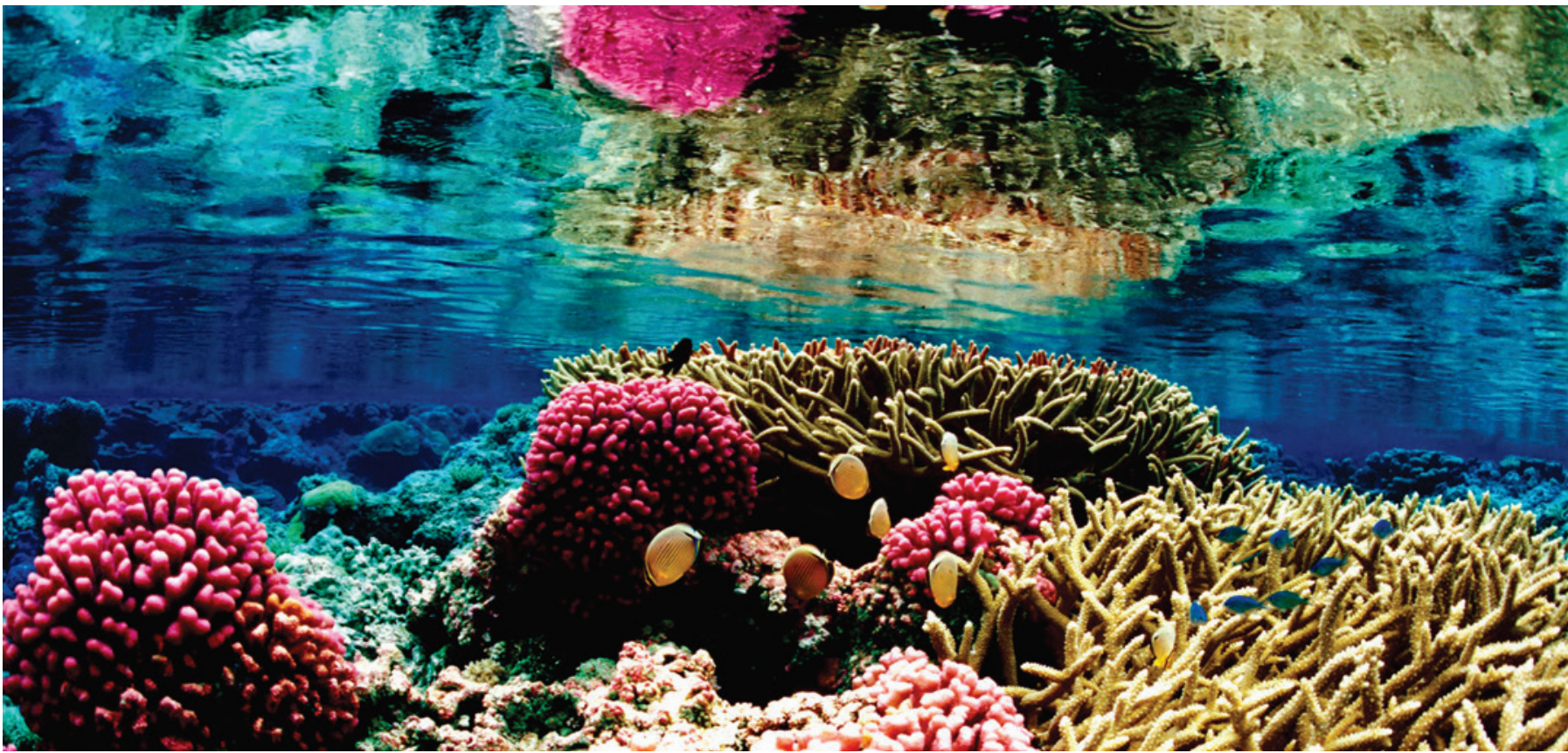

Coral gardens in the Palmyra Atoll and Kingman Reef national wildlife refuges, protected under the Pacific Remote Islands Marine National Monument.

will we be able to resist the ever-growing pressures that transnational crime, corruption and increasing population place on wildlife and wild lands.

\section{EMILY DARLING}

\section{Conserve climate refuges}

David H. Smith conservation research fellow, University of North Carolina and the Wildlife Conservation Society

Climate change raises a triple threat that existing marine protected areas were not designed to defend against. Warming, rising and acidifying seas threaten global marine biodiversity and ecosystem services. Even in protected areas, El Niño events and ocean heatwaves can bleach and destroy vast areas of healthy coral reefs - the canary in the coal mine of climate change.

To give coral reefs and other global ecosystems time to adapt, we need to identify areas that will escape the worst impacts of a changing climate. These should be protected as 'climate refuges' - areas that will experience less change over the coming decades. In the northern Mozambique channel and the Raja Ampat archipelago in Indonesia, for instance, upwelling and ocean gyres bring cool water that has allowed fragile corals to escape bleaching. Emerging evidence suggests that several million years ago, rare reef habitats that escaped rising temperatures provided the blueprint for contemporary diversity. Today, climate refuges may be our best hope for protected areas to sustain healthy coral reefs into the future.

The first steps are to catalyse local communities, national governments and multilateral agencies to protect such areas. Urgently, we need to coordinate, fund and implement a global plan to link networks of climate refuges for all ecosystems: coral reefs, tropical rainforests, Arctic tundra and beyond. The World Parks Congress must lay the groundwork to incorporate climate refuges into conservation portfolios and protected areas.

PETER J. S. JONES

\section{Assess governance structures}

\section{Researcher on natural resource governance approaches, University College London}

Projects such as the International Union for Conservation of Nature's Green List are beginning to evaluate the effectiveness of protected areas systematically. This will help to shift the focus of conservation efforts from targets assessed just by hectares to other, more-meaningful objectives, focused on effectiveness. But to learn from successes and failures, we must also evaluate governance systems.

These systems incorporate roughly five approaches: top-down regulation, bottomup participation, market mechanisms, awareness-raising and knowledge-sharing. We need to know what makes each effective, and how these different approaches can be combined to reinforce each other.

On Chumbe Island, a private island park off the coast of Zanzibar in East Africa, diverse approaches mesh to form a strong governance framework. In 1994, a nonprofit company was granted property rights to the island and its surrounding waters, along with obligations to the local environment and community. For example, income from ecotourists is invested in local schools and other community projects. The local police assist in enforcing a no-fishing zone, and anti-poaching patrols provide community services, such as helping fishing boats in peril.

Projects with fewer approaches are less robust. Consider the Cres-Lošinj Special Marine Reserve in Croatia. Here local authorities instituted the Adriatic Sea's largest marine protected area for dolphins, only for the designation to lapse when commercial developers touted the jobs and other economic benefits that a recreational marina could provide. In this case, top-down regulation, along with other governance approaches, might yet prove effective. The European Commission could oblige the Croatian government to reinstate protection as a condition of joining the European Union.

Too often, conservation discussions descend into unproductive debates about which governance approach is best, but the best solution varies with context. We need to learn the principles to match combinations of approaches with situations. The key to resilience is diversity - both of species in ecosystems and approaches in governance systems. - 